\title{
Higher education attainment does not improve the adult employment outcomes of adolescents with ill health
}

\author{
Emily Callander \\ James Cook University \\ Deborah J. Schofield \\ University of Sydney \\ Rupendra N. Shrestha \\ University of Sydney
}

\begin{abstract}
This paper assesses whether attaining a higher education improves the chances of employment in adulthood amongst those who had a chronic health condition in adolescence. Using longitudinal analysis of twelve waves of the nationally representative Household Income and Labour Dynamics in Australia Survey, conducted between 2001 and 2012, a cohort of adolescents aged 15 to 21 in Wave 1 were followed through to age $24(n=624)$. The results show that those who did have a chronic health condition during adolescence were 2.4 times more likely to not be employed at age 24 compared to those who did not have a chronic health condition (95\% Cl: $1.4-4.4, \mathrm{p}=0.0024)$. The results were adjusted for age, sex, education attainment at age 24, health status at age 24 and household income poverty status at age 24 . Amongst those who did have a chronic health condition during adolescence there was no significant difference in the likelihood of being employed for those with a Year 12 and below $(p=0.1087)$ level of education attainment or those with a Diploma, Certificate III or IV ( $p=0.6366)$ compared to those with a university degree. Education attainment was not shown to mitigate the impact of having a chronic health condition during adolescence on adult employment outcomes.
\end{abstract}

Keywords: employment; chronic health conditions; poverty; living standards; longitudinal.

Numerous studies have documented the association between health and labour force participation (Bartel \& Taubman, 1979; Cai, 2007; Cai \& Kalb, 2004; Campolieti, 2002; Kraut, Walld, Tate, \& Mustard, 2001; Pandey, 2009; Roberts, Rice, \& Jones, 2008; Stern, 1989). For example, Nepal, Payne and Brown (2009) found that one in two working aged Australians with poor health were not in the labour force, compared to one in five of those with good health. While these studies are predominantly cross-sectional in nature and examine current health status, there is a small but growing body of literature, predominantly from the United States and the United Kingdom, that identifies the detrimental impact childhood ill health has on adult labour force participation (Case, Fertig, \& Paxson, 2005; Case \& Paxson, 2010; Goodman, Joyce, \& Smith, 2011; Smith, 2009; Smith \& Smith, 2010). A recent systematic review has documented the negative influence poor health has on the employment of younger people (Hale, Bevilacqua, \& Viner, 2015). Given the known economic consequences of labour force exit in virtually all Organisation for Economic Cooperation and Development (OECD)

Corresponding author: Emily Callander (emily.callander@jcu.edu.au ) 
countries (Organisation for Economic Co-operation and Development, 2007), childhood poor health has the potential to detrimentally impact upon individuals for the rest of their lives. However, the impediment of chronic disease may be offset by a higher education. Higher levels of education attainment are known to be strongly linked with better chances of labour force participation within Australia (Laplagne, Glover, \& Shomos, 2007; OECD, 2006; Productivity Commission, 2005). Education has long been considered to be a key form of human capital (Schultz, 1962). Within Australia, education has been specifically identified as giving disadvantaged individuals the ability to participate in the labour force (Council of Australian Governments, 2006).

This paper has two aims, firstly to determine whether those who suffered a chronic health condition during adolescence had lower rates of employment in adulthood after taking into consideration tertiary education attainment. The second aim sought to compare the adult employment outcomes of those who achieved different levels of education attainment amongst those who suffered a chronic health condition during adolescence. Given the documented influence of education attainment on labour force participation it is expected that after taking into consideration tertiary education attainment there will be little difference in adult employment outcomes between those who did experience a chronic health condition during adolescence and those that did not; and that those with a tertiary level of education attainment amongst those who experienced poor health during adolescence will have better employment outcomes than those with lower levels of education attainment.

\section{Method}

\section{Data set sampling and weighting}

This was a longitudinal study, which utilised the Household Income and Labour Dynamics in Australia (HILDA) Survey to assess changes in education, health and employment in the Australian population aged 15 to 21 years in 2001 up until the time they turned 24 . The HILDA survey is a longitudinal survey of private Australian households conducted annually since 2001. The data was nationally representative of the Australian population living in private dwellings and aged 15 years and over (Summerfield et al., 2010). The survey sampling unit for Wave 1 was the household, with all individual members of the selected households followed over the life of the survey, however, only those aged 15 and over had detailed individual information recorded. Households are generally used as the sampling unit for panel datasets concerned with eliciting information at both the individual and household level (Lynn, 2009). The reference population for the HILDA sample selection was all members of private dwellings in Australia, except overseas residents, including diplomatic personnel, in Australia; residents of institutions such as hospitals, military and police barracks, correctional institutions and monasteries and non-private dwellings such as hotels; and people living in very remote sparsely populated areas. Household sampling was conducted in a three-stage approach. This coverage broadly aligns with that used by the Australian Bureau of Statistics, for labour force participation measurements (Australian Bureau of Statistics, 2001). Initially 488 Census Collection Districts (each containing 200 to 250 households) from across Australia were randomly selected. Then within each of these districts, 22 to 34 dwellings were randomly selected. Finally, up to three households within each dwelling were randomly selected to be part of the sample.

The initial household cross-sectional weights in Wave 1 (upon which the cross-sectional weights in subsequent waves are dependent) were derived from the probability of selecting the household and were calibrated so that the weighted estimates matched known benchmarks for number of adults by number of children and state by part of state. The person-level weights were based on the household weights and then calibrated so that person weights matched known benchmarks for sex by age, state by part of state, state by labour force status, marital status and household composition. Longitudinal weights adjusted 
for attrition and benchmarked against the characteristics of Wave 1. For a detailed description of HILDA weighting see Watson (2012).

\section{Study design}

Individuals who were aged between 15 and 21 in Wave 1 (2001) of the HILDA dataset were identified. These individuals were then followed through the later waves until the age of 21 , and those who had a chronic health condition at any time in this time period were identified. These people were referred to as 'those who experienced a chronic health condition during adolescence'. A chronic health condition in the HILDA dataset was defined as "any long-term health condition, impairment or disability that restricts everyday activities, and has lasted or is likely to last, for 6 months or more" (HILDA Project Director Melbourne Institute of Applied Economic and Social Research, 2012). For individuals who were aged 15 in Wave 1, their chronic health condition status was assessed in each wave between Wave 1 and Wave 7 (the year they turned 21); for individuals who were aged 16 in Wave 1, their chronic health condition status was assessed in each wave between Wave 1 and Wave 6; and so on until for individuals who were aged 21 in Wave 1, their chronic health condition status in Wave 1 only was assessed. This is detailed in Table 1.

Table 1: Wave and year that respondents of various ages in HILDA Wave 1 were 21 and 24 years of age

\begin{tabular}{ccc}
\hline Age in Wave 1 (2001) & $\begin{array}{c}\text { Wave and Year respondent } \\
\text { was age 21 }\end{array}$ & $\begin{array}{c}\text { Wave and Year } \\
\text { respondent was age 24 }\end{array}$ \\
\hline 15 & Wave 7 (2007) & Wave 10 (2010) \\
\hline 16 & Wave 6 (2006) & Wave $9(2009)$ \\
\hline 17 & Wave 5 (2005) & Wave $8(2008)$ \\
\hline 18 & Wave 4 (2004) & Wave 7 (2007) \\
\hline 19 & Wave 3 (2003) & Wave 6 (2006) \\
\hline 20 & Wave 2 (2002) & Wave 5 (2005) \\
\hline 21 & Wave 1 (2001) & Wave 4 (2004)
\end{tabular}

Highest level of education attainment at age 24 was then identified for the individuals who were aged between 15 and 21 in Wave 1. Education attainment was grouped into three categories: 1) University degree (postgraduate degree, bachelor degree); 2) Diploma, Certificate III or Certificate IV (post High School, but not University); and 3) Year 12 and Year 11 or below. Individuals were identified as being either employed (in full time or part time employment) or not employed (unemployed but looking for full time or part time work, or not in the labour force) at age 24.

\section{Statistical analysis}

Descriptive analysis was initially undertaken, comparing the number and proportion of people who at age 24 had different levels of highest education attainment, overall health 
status at age $24^{1}$, and were in households who were in income poverty at age $24^{2}$, for those who had a chronic health condition during adolescence and those that did not.

A logistic regression model was constructed to assess the odds ratio of having a tertiary degree as the highest level of education attainment at age 24 for those who had a chronic health condition during adolescence, compared to those who did not. Those who did not have a chronic health condition during adolescence were used as the reference group, and the models were adjusted for age in Wave 1, and sex.

Employment status at age 24 was then assessed. A logistic regression model was built to compare the odds of not being employed at age 24 for those who had and did not have a chronic health condition during adolescence. The model was adjusted for age in Wave 1, sex, health status at age 24, and household income poverty status at age24. People who had a health condition during adolescence were used as a reference group. The logistic regression model was then repeated with the addition of highest level of education attainment at age 24 as a confounding variable.

The analysis was then limited to those who had a chronic health condition during adolescence. A logistic regression model was built to compare the odds of being employed at age 24 for those who had a university degree, a Diploma, Certificate IV or III, and Year 12 or Year 11 and below. The model was adjusted for age in Wave 1, sex, health status at age 24 , and household income poverty status at age24. People whose highest level of education attainment was Year 12 or Year 11 and below were used as the reference group.

The analysis was undertaken on weighted data. The HILDA survey contained longitudinal weights, which ensure that records were representative of the Australian population. All analysis was conducted using SAS V9.2 (SAS, 2016). Statistical significance was set at a $5 \%$ level.

\section{Results}

\section{Adult outcomes of those with a chronic health condition in adolescence}

There were 624 records of people who were aged 15 to 21 years at their last birthday as of 30 June 2001, on the HILDA Wave 1 dataset. These records represented 1,588,800 individuals within the Australian population in 2001 . Of this group, 406,000 people (or $26 \%$ of this population) had a chronic health condition between the age of 15 and 21 .

Of the people who had a chronic health condition during adolescence, $48 \%$ had poor overall health status and $10 \%$ were in income poverty at age 24 . Whereas $33 \%$ of people who did not have a chronic health condition during adolescence reported having poor overall health status at age 24 , and $4 \%$ were in income poverty.

Table 2 compares the highest level of education attainment at age 24 for the population of individuals who were aged 15 to 21 in 2001. A lower proportion of people who experienced a chronic health condition during adolescence had a university degree, compared with those who did not experience a chronic health condition. A higher proportion of those who had a

\footnotetext{
${ }^{1}$ Health status at age 24 was measured using the SF-36 health scale (IQOLA, 2009) and the SF-6D (SF-36) health utility score (Brazier, Harper, \& Deverill, 2002), which was recorded on the HILDA dataset. The cut-off point for being disadvantaged in the dimension of health was having a health utility score lower than the average score for one's age group (Callander, Schofield, Shrestha, \& Kelly, 2012; Utah Department of Health, 2001).

${ }^{2}$ People's household income poverty status at age 24 was identified utilizing OECD-modified equivalence scales and the $50 \%$ of the median income poverty line, as is standard practice in Australia (see for example Saunders \& Bradbury, 2006; Saunders, Hill, \& Bradbury, 2007). This takes into consideration the income of each member of the household in assessing income poverty status. People whose equivalised household income fell below $50 \%$ of the median income for the population in the year the person was 24 were deemed to be in income poverty at age 24.
} 
chronic health condition in adolescence had Year 12, or Year 11 and below as their highest level of education attainment. After adjusting for age and sex those who had a chronic health condition during adolescence had 0.3 times the odds of having a university degree at age 24 than those who did not experience a chronic health condition $(95 \% \mathrm{Cl}: 0.2-0.5, \mathrm{p}<.0001)$.

Table 2: Highest level of education attainment at age 24 amongst individuals who were aged 15 to 21 in 2001

\begin{tabular}{|c|c|c|c|c|c|}
\hline \multirow{2}{*}{\multicolumn{2}{|c|}{$\begin{array}{c}\text { Health status during } \\
\text { adolescence }\end{array}$}} & \multicolumn{3}{|c|}{$\begin{array}{c}\text { Highest level of education attainment at } \\
\text { age } 24\end{array}$} & \multirow[b]{2}{*}{ Total } \\
\hline & & University & Diploma & Year 12, & \\
\hline \multirow{3}{*}{$\begin{array}{l}\text { Did not have a } \\
\text { chronic health } \\
\text { condition in } \\
\text { adolescence }\end{array}$} & Sample (n) & 146 & 117 & 201 & 464 \\
\hline & $\begin{array}{l}\text { Population } \\
(\mathrm{N})\end{array}$ & 378000 & 293700 & 511200 & 1182800 \\
\hline & $\begin{array}{c}\% \text { of } \\
\text { population }\end{array}$ & $32 \%$ & $25 \%$ & $43 \%$ & $100 \%$ \\
\hline \multirow{3}{*}{$\begin{array}{l}\text { Had a chronic } \\
\text { health condition in } \\
\text { adolescence }\end{array}$} & Sample (n) & 21 & 48 & 91 & 160 \\
\hline & $\begin{array}{c}\text { Population } \\
(\mathrm{N})\end{array}$ & 52000 & 135500 & 218500 & 406000 \\
\hline & $\begin{array}{c}\% \text { of } \\
\text { population }\end{array}$ & $13 \%$ & $33 \%$ & $54 \%$ & $100 \%$ \\
\hline
\end{tabular}

\section{Employment outcomes and education attainment}

$74 \%$ of those who had a chronic health condition during adolescence were employed at age 24 and $26 \%$ were not employed. 91\% of those who did not experience a chronic health condition during adolescence were employed at age 24 , and $9 \%$ were not employed.

Before adjusting for highest level of education attainment, those who had a chronic health condition had 2.8 times the odds of not being employed at age 24 than those without a chronic health condition (95\% Cl: $1.5-5.1, \mathrm{p}=0.0008)$. This was adjusted for age in Wave 1 , sex, health status at age 24 and household income poverty status at age 24 . After adding highest level of education attainment to the model, those who had a chronic health condition had 2.4 times the odds of not being employed at age 24 than those without a chronic health condition (95\% Cl: $1.4-4.4, \mathrm{p}=0.0024)$. This was adjusted for age in Wave 1 , sex, highest level of education attainment at age 24, health status at age 24 and household income poverty status at age 24 .

The analysis was then limited to those who had a chronic health condition during adolescence. Table 3 shows the odds ratio of being employed at age 24 for those with different levels of education attainment, controlling for age, sex, health status and household income poverty status at age 24 . There was no significant difference in the likelihood of being employed for those with a Year 12, or Year 11 and below level of education attainment or those with a Diploma, Certificate III or IV compared those with a university degree. 
Table 3: Odds ratio of being employed (either full time or part time) at age 24, amongst individuals aged 15 to 21 in 2001 who had a chronic health condition during adolescence.

\begin{tabular}{lcccccc}
\hline $\begin{array}{l}\text { Highest } \\
\text { level of } \\
\text { education } \\
\text { attainment } \\
\text { at age 24 }\end{array}$ & $\begin{array}{c}\text { Sample } \\
\text { (n) }\end{array}$ & $\begin{array}{c}\text { Population } \\
\text { (N) }\end{array}$ & $\begin{array}{c}\text { Proportion } \\
\text { of } \\
\text { population } \\
\text { employed }\end{array}$ & $\begin{array}{c}\text { OR of } \\
\text { being } \\
\text { employed }\end{array}$ & 95\% Cl & p-value \\
\hline $\begin{array}{l}\text { University } \\
\text { degree }\end{array}$ & 21 & 52000 & $87 \%$ & & REFERENCE & \\
\hline $\begin{array}{l}\text { Diploma, } \\
\text { Certificate III } \\
\text { or IV }\end{array}$ & 48 & 135500 & $85 \%$ & 0.6 & $0.1-5.0$ & 0.6366 \\
\hline $\begin{array}{l}\text { Year 12, } \\
\text { Year 11 or } \\
\text { below }\end{array}$ & 91 & 218500 & $65 \%$ & 0.2 & $0.0-1.5$ & 0.1087 \\
\hline
\end{tabular}

${ }^{a}$ Adjusted for age, sex, health status at age 24 and household income poverty status at age 24

\section{Discussion}

This study has shown that even after controlling for highest level of education attainment, those who had a chronic health condition during adolescence still had a lower likelihood of being employed at age 24 . For people who experienced a chronic health condition during adolescence, having a University degree did not improve the chances of employment. This is the first study to document whether or not education attainment can mitigate the negative impact of chronic health conditions on the labour force participation of young people. Other studies have identified that those who experience poor health during adolescence have lower rates of employment during adulthood (Case et al., 2005; Case \& Paxson, 2010; Currie \& Stabile, 2004; Currie, Stabile, Manivong, \& Roos, 2008; Goodman et al., 2011; Haas, 2006; Haas \& Fosse, 2008; Hack et al., 2002; Jackson, 2009; Smith, 2009; Smith \& Smith, 2010). However, other studies have not explored if education attainment may mitigate these impacts. This is a significant omission given that policies to improve the lives of disadvantaged children and improve their labour force participation are usually based upon improving education attainment (COAG Reform Council, 2009: xv; Social Inclusion Group, 2011; Social Inclusion Unit, 2009).

While education is often cited as a means of improving the lives of disadvantaged children, little attention has been given to childhood chronic health conditions in policies to improve living standards of children. This study has shown that of the cohort of adolescents aged 15 to 21 in 2001, 26\% experienced a chronic health condition between 2001 and the time they turned 21 . The study has also shown that only $74 \%$ of these people were employed when they were 24 , compared to $91 \%$ of the people who did not experience a chronic health condition. Furthermore, after controlling for level of highest education attainment and adult health status, those who did not experience a health condition during adolescence were still more than twice as likely to be employed by comparison. This may have particular significance at a time when youth unemployment rates across Australia are relatively high (Australian Bureau of Statistics, 2016) and governments are giving significant attention to improving the employment rates of young Australians (Australian Government, 2015).

Labour force participation is of significant importance for long-term health and wellbeing, hence the importance of measuring and identifying what influences labour force participation of young people. Unemployment is adversely associated with people's health, particularly their mental health (Hammarström \& Janlert, 2002; Marmont, 2005; Paul \& Moser, 2009; 
Viner et al., 2012), as is non-stable employment (Keuskamp, Ziersch, Baum, \& LaMontagne, 2013). Furthermore, labour force participation is an important means of social interaction for people with poor health (Callander \& Schofield, 2013), which in turn has documented health benefits (Bloom, Stewart, Johnston, Banks, \& Fobair, 2001; Bygnen, Konlaan, \& Johansson, 1996; Glass, Mendes de Leon, Martottoli, \& Berkman, 1999; House, Robbins, \& Metzer, 1982; Kaplan et al., 1988; Lynch et al., 2008; Orth-Gomer, Rosengren, \& Wilhelmsen, 1993; Uchino, Cacioppo, \& Kiecolt-Glaser, 1996). People who had a chronic health condition during childhood may have their long term health further adversely affected through poorer socioeconomic circumstances as a result of their lower rates of workforce participation.

Assisting young people with chronic health conditions to enter the labour force should be seen as a priority when seeking to address youth unemployment. However, this paper has shown that gaining a tertiary level of education attainment made little difference to the likelihood of young people with a chronic health condition participating in the workforce. Given this, policies to prevent and manage chronic health conditions during adolescence require more weighting, in the way that policies to improve education attainment have been prioritized if the aims is to advance the living standards of disadvantaged children. 


\section{References}

Australian Bureau of Statistics. (2001). Labour Statistics: Concepts, Sources and Methods (ABS Cat. No. 6102.0). Canberra: ABS.

Australian Bureau of Statistics. (2016). Labour Force, Australia, Feb 2016 ABS Cat. No. 6202.0. Retrieved from Canberra:

Australian Government. (2015). Youth Employment Strategy Budget 2015-16. Canberra: Australian Government.

Bartel, A., \& Taubman, P. (1979). Health and labour market success: the role of various diseases. The Review of Economics and Statistics, LXI(1), 1-8.

Bloom, j. R., Stewart, S. L., Johnston, M., Banks, P., \& Fobair, P. (2001). Sources of support and the physcial and mental well-being of young women with breast cancer. Social Science and Medicine, 53(11), 1513-1524.

Brazier, J. E., Harper, R. J. A., \& Deverill, M. (2002). The estimation of a preference-based measure of health from the SF-36. Journal of Health Economics, 21, 271-292.

Bygnen, L. O., Konlaan, B. B., \& Johansson, S. E. (1996). Attendence at cultural events, reading books or periodicals, and making music or singing in a choir as determinants for survival: Sweedish interview survyey of living standards. Bmj, 313(1577).

Cai, L. (2007). The relationship between health and labour force particpation: Evidence from a panel data simultaneous equation model. Retrieved from Melbourne:

Cai, L., \& Kalb, G. (2004). Health status and labour force particpation: Evidence from the HILDA data. Retrieved from Melbourne:

Callander, E., \& Schofield, D. (2013). The relationship between employment and social participation amongst Australians with a disabling chronic health condition: a crosssectional analysis. BMJ Open, 3(e002054).

Callander, E., Schofield, D., Shrestha, R., \& Kelly, S. J. (2012). Health and functional capacity - capturing capability limitations in measures of health. Health Sociology Review, 21(3), 322-331.

Campolieti, M. (2002). Disability and the labour force particpation of older men in Canada. Labour Economics, 9, 405-432.

Case, A., Fertig, A., \& Paxson, C. (2005). The lasting impact of childhood health and circumstance. Journal of Health Economics, 24, 365-389.

Case, A., \& Paxson, C. (2010). Causes and consequences of early life health NBER Working Paper Series. Cambridge: National Bureau of Economic Research.

COAG Reform Council. (2009). National Education Agreement: Baseline performance report for 2008. Retrieved from Sydney:

Council of Australian Governments. (2006). COAG Communique 10 Februrary 2006.

Currie, J., \& Stabile, M. (2004). Child mental health and human capital accumulation: The case of ADHD NBER Working Paper Series. Cambridge: National Bureau of Economic Research.

Currie, J., Stabile, M., Manivong, R., \& Roos, L. L. (2008). Child health and young adult outcomes NBER Working Paper Series. Cambridge: National Bureau of Economic Research.

Glass, T. A., Mendes de Leon, C., Martottoli, R. A., \& Berkman, L. F. (1999). Population based study of social and productive activities as predictors of survival among elderly Americans. Bmj, 319(7208), 478-483.

Goodman, A., Joyce, R., \& Smith, J. P. (2011). The long shadow cast by childhood physical and mental problems on adult life. Proceedings of the National Academy of Sciences, 108(15), 6032-6037.

Haas, S. A. (2006). Health Selection and the Process of Social Stratification: The Effect of Childhood Health on Socioeconomic Attainment. Journal of Health and Social Behavior, 47(4), 339-354.

Haas, S. A., \& Fosse, N. E. (2008). Health and the Educational Attainment of Adolescents: Evidence from the NLSY97. Journal of Health and Social Behavior, 49(2), 178-192. 
Hack, M., Flannery, D. J., Schluchter, M., Cartar, L., Borawski, E., \& Klein, N. (2002). Outcomes in young adulthood for very low birthweight infants. The New England Journal of Medicine, 346(3), 149-157.

Hale, D. R., Bevilacqua, L., \& Viner, R. M. (2015). Adolescent health and adult education and employment: a systematic review. Pediatrics, 136(1), 128-140.

Hammarström, A., \& Janlert, U. (2002). Early unemployment can contribute to adult health problems: results from a longitudinal study of school leavers. Journal of epidemiology and community health, 56(8), 624-630.

HILDA Project Director Melbourne Institute of Applied Economic and Social Research. (2012). Data Dictionary Release 10.0. Melbourne: Melbourne Institute of Applied Economic and Social Research.

House, J. S., Robbins, C., \& Metzer, H. L. (1982). The association of social relationships and activities with mortality: Prospective evidence from the Tecumsen Community Health Study. American Journal of Epidemiology, 116(1), 123-140.

IQOLA. (2009). The SF Questionnaires. Retrieved from http://www.iqola.org/instruments.aspx

Jackson, M. I. (2009). Understanding links between adolescent health and educational attainment. Demography, 46(4), 671-694.

Kaplan, G. A., Salonen, J. T., Cohen, R. D., Brand, R. J., Syme, S. L., \& Puska, P. (1988). Social connections and mortality from all causes and from CVD: prospective evidence from eastern Finaland. American Journal of Epidemiology, 128(2), 370-380.

Keuskamp, D., Ziersch, A. M., Baum, F. E., \& LaMontagne, A. D. (2013). Precarious employment, psychosocial working conditions, and health: Cross-sectional associations in a population-based sample of working Australians. American journal of industrial medicine, 56(8), 838-844.

Kraut, A., Walld, R., Tate, R., \& Mustard, C. (2001). Impact of Diabetes on employment and income in Manitoba, Canada. Diabetes Care, 24(1), 64-68.

Laplagne, P., Glover, M., \& Shomos, A. (2007). Effects of health and education on labour force particpation. Retrieved from Canberra:

Lynch, E. B., Butt, Z., Heinemann, A., Victorson, D., Nowinski, C. J., Perez, L., \& Cella, D. (2008). A qualitiative study of quality of life after stroke: The importance of social relationships. Journal of rehabilitation medicine, 40, 518-523.

Lynn, P. (2009). Methods for longitudinal surveys. In P. Lynn (Ed.), Methodology of longitudinal surveys. Chichester: Wiley.

Marmont, M. (2005). Social determinants of health inequalities. The Lancet, 365(March 19), 1099-1104.

Nepal, B., Payne, A., \& Brown, L. (2009). Health, wealthy and wise? The relationship between health, employment and earning in Australia. Retrieved from Sydney:

OECD. (2006). Labour Force Participation by Level of Educational Attainment Education at a Glance 2006: OECD Indicators. Paris: OECD Publishing.

Organisation for Economic Co-operation and Development. (2007). Sickness, disability and work: breaking the barriers. Retrieved from Paris:

Orth-Gomer, K., Rosengren, A., \& Wilhelmsen, L. (1993). Lack of social support and incidenceof coronary heart disease in middle-aged Sweedish men. Psychosomatic Medicine, 55(1), 37-43.

Pandey, M. K. (2009). Labour force particpation among Indian elderly: does health matter. Retrieved from

Paul, K. I., \& Moser, K. (2009). Unemployment impairs mental health: Meta-analyses. Journal of Vocational behavior, 74(3), 264-282.

Productivity Commission. (2005). Economic Implications of an Ageing Australia. Retrieved from Canberra:

Roberts, J., Rice, N., \& Jones, A. M. (2008). Early retirement and inequality in Britain and Germany: How important is health? Retrieved from Sheffield:

SAS Institute. (2016) SAS 9.2, SAS Institute: North Carolina, USA. 
Saunders, P., \& Bradbury, B. (2006). Monitoring Trends in Poverty and Income Distribution: Data, Methodology and Measurement. The Economic Record, 82(258), 341-364.

Saunders, P., Hill, T., \& Bradbury, B. (2007). Poverty in Australia: Sensitivity Analysis and Recent Trends. Retrieved from Sydney:

Schultz, T. W. (1962). Reflections on investment in man. The Journal of Political Economy, $L X X(5), 1-8$.

Smith, J. P. (2009). The impact of childhood health on adult labour market outcomes. The Review of Economics and Statistics, 91(3), 478-489.

Smith, J. P., \& Smith, G. C. (2010). Long-term economic costs of psychological problems during childhood. Social Science and Medicine, 71, 210-215.

Social Inclusion Group. (2011). Supporting children at greatest risk of long term disadvantage Retrieved from http://www.socialinclusion.gov.au/Initiatives/Pages/Support.aspx

Social Inclusion Unit. (2009). Social Inclusion and Early Childhood Development. Retrieved from Canberra:

Stern, S. (1989). Measuring the effect of disability on labour force particpation. The Journal of Human Resources, XXIV(3), 361-395.

Summerfield, M., Dunn, R., Freidin, S., Hahn, M., Ittak, P., Kecmanovic, M., .. . Wooden, M. (2010). HILDA User Manual - Release 10. Melbourne: Melbourne Institute of Applied Economic and Social Research.

Uchino, B. N., Cacioppo, J. T., \& Kiecolt-Glaser, J. K. (1996). The relationship between social support and physiological processes: a review with emphasis on underlying mechanisms and implications for health. Psychological Bulletin, 119(3), 488-531.

Utah Department of Health. (2001). Interpreting the SF-12. Retrieved from

Viner, R. M., Ozer, E. M., Denny, S., Marmot, M., Resnick, M., Fatusi, A., \& Currie, C. (2012). Adolescence and the social determinants of health. The Lancet, 379(9826), 1641-1652.

Watson, N. (2012). Longitudinal and Cross-sectional Weighting Methodology for the HILDA Survey, HILDA Project Technical Paper Series No. 2/12. Retrieved from Melbourne, Australia:

\section{Biographical notes}

Dr Callander is a Senior Research Fellow and health economist specialising in measuring the impact of ill health on family living standards.

Professor Schofield is Chair of Health Economics and specialising in utilising microsimulation modelling to quantify the productivity impacts of chronic disease.

Rupendra N. Shrestha is a Research Fellow and biostatistician who specialises in modelling productivity impacts of chronic disease. 